\title{
Takotsubo Cardiomyopathy Associated with Levothyroxine over-Replacement
}

\section{Ana Margarida Balsa, Joana Guimarães, Ana Raquel Ferreira and Rosa Dantas Centro Hospitalar do Baixo Vouga, Portugal}

\section{Background}

Takotsubo cardiomyopathy (TC) is characterized by acute, transient left ventricular apical ballooning precipitated by emotional or physiologically stressful stimuli and has been previously associated with Grave's disease based on few clinical reports.

latrogenic hyperthyroidism on patients under levothyroxine replacement therapy

for hypothyroidism had never been reported as a cause of TC.

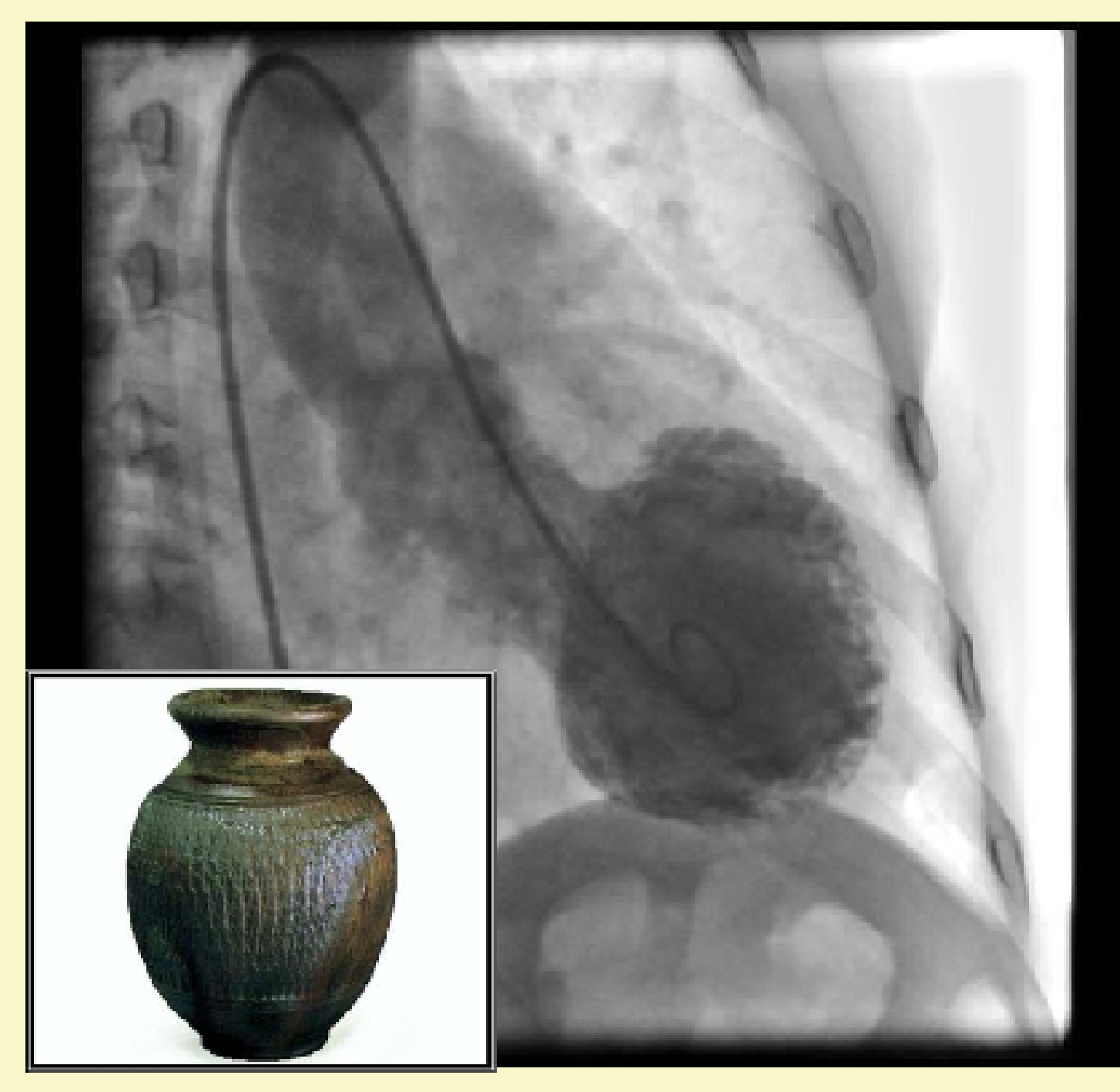

\section{Clinical cases}

IDENTIFICATION MMMF, female, caucasian, 74 years old $\quad$ MMFSA, female, caucasian, 48 years old

\begin{tabular}{ll}
\hline HISTORY OF PRESENT & $\begin{array}{l}\text { Sudden and severe pre-cordial pain, described } \\
\text { sensation of tightness that began after mild effort } \\
\text { ILNESS }\end{array}$ \\
$\begin{array}{ll}\text { and was accompanied by nausea. Refers unusua } \\
\text { amount of stress in the past } 2 \text { weeks. }\end{array}$ \\
PAST MEDICAL HISTORY & $\begin{array}{l}\text { - Autoimmune thyroiditis with hypothyroidism } \\
\text { - Osteoporosis } \\
\text { - Mitral valve regurgitation } \\
\text { - Reumathoid arthritis }\end{array}$
\end{tabular}

\section{MEDICATION}

\section{COMPLEMENTARY}

DIAGNOSIS EXAMS

HOSPITAL COURSE
- Levothyroxine $1,25 \mathrm{mg}$ id $(2,27 \mathrm{mcg} / \mathrm{Kg})$

- Calcium carbonate and colecalciferol 1250mg + 40010 id

-Sivastatin 20mg id

-Escitalopram 10mg id

-Macrogol 10000mg id

ECG - ST-segment elevation in the anterior precordial leads

Echocardiogram - anterio-inferior apical hipokinesia. LVEF $43 \%$

\section{Elevation of chardiac markers}

Catheterisation with no significant coronary lesions, ventriculogram with marked anterio-inferior apical hipokinesia

TSH of $0,21 \mathrm{mIU} / \mathrm{L}$

Levothyroxine dose was reduced.

After admition the patient remained asyptomatic, the control echocardiogram showed improvement of the apical hypokinesis, the analysis showed normalization of cardiac biomarker levels.
Pre-cordial pain that irradiated to the left arm, with palpitations and dyspnea. The pain started after emotional stress.

- Autoimmune thyroiditis with hypothyroidism

- Hypertension

- Dyslipidemia

- Laparoscopic apendicectomy in 2010,

- Hyterectomy in 2012

-Levothyroxine $1,5 \mathrm{mg}$ id $(1,85 \mathrm{mcg} / \mathrm{Kg})$

-Acetylsalicylic acid 100mg id

- Telmisartan/hydrochlorothiazide $40 / 12,5 \mathrm{mg}$ id

-Pitavastatin $2 \mathrm{mg}$ id

ECG - sinus tachycardia (144bpm) with deep T-wave inversion and QT interval prolongation

Echocardiogram - apical hypokinesia

Elevation of chardiac markers

Coronary catheterisation with no significant lesions TSH of $0,07 \mathrm{mIU} / \mathrm{L}$

Levothyroxine dose was reduced.

The patient denyed further pain episodes. The discharge echocardiogram revealed an improvement on apical contractility.

\section{Conclusion}

As they add up to the growing evidence of the association of TC and thyrotoxicosis, these cases emphasize the importance of correct dose adjustment on patients under levothyroxine replacement therapy and stress that TSH should be determined in all patients presenting with acute coronary syndrome and typical finding of TC. 